\title{
Tan Without the Sun: A Case of Nelson's Syndrome
}

\author{
Guntur Darmawan, Daveric A. Pagsisihan, Aimee A. Andag-Silva \\ Department of Internal Medicine, De La Salle University Medical Center, Dasmariñas, Cavite, Philippines
}

\begin{abstract}
Nelson's syndrome (NS) is a rare complication following bilateral adrenalectomy. ${ }^{1}$ We report a case of NS in a 53 -yearold female with headache and generalized hyperpigmentation. She had bilateral adrenalectomy for Cushing's syndrome (CS) secondary to adrenal hyperplasia 22 years ago. Early routine surveillance and extensive patient discussion regarding the lifelong impact of NS is imperative.
\end{abstract}

Keywords: Nelson's syndrome, bilateral adrenalectomy, Cushing's syndrome

\section{INTRODUCTION}

Nelson's Syndrome (NS), first reported by Don Nelson and colleagues in 1958, is a potential iatrogenic complication after bilateral adrenalectomy. ${ }^{1}$ Although the prevalence of NS after bilateral adrenalectomy varies between 8 to $29 \%$, the procedure is not frequently performed. ${ }^{2-4}$ In the United States, the annual rate of bilateral adrenalectomy for Cushing's syndrome (CS) was reported to be 0.32 per 100,000 hospital discharges in $2000 .^{5}$ Cushing's Syndrome is the clinical manifestation of chronic exposure to excessive glucocorticoids, either from an exogenous or an endogenous source. Endogenous CS is a rare disease, with an annual incidence of 2 to 4 cases per million. Of these, $70 \%$ is due to Cushing's disease (CD); ACTH-independent bilateral adrenal hyperplasia is an infrequent cause. ${ }^{6}$ While there is no available Philippine data regarding the annual rate of bilateral adrenalectomy, a thorough literature search yielded only one published case of NS in a 23-year-old female after bilateral adrenalectomy. ${ }^{7}$

\section{CASE}

A 53-year-old Filipino woman consulted our institution for a 11/2-month history of headache in March 2012. In 1989, the patient was seen in another center for amenorrhea, headache, polyuria, polydipsia, polyphagia and easy bruising. These were accompanied by the development of hypertension, moon facies, prominence of the dorsocervical fat pad, pitting edema of legs, and maculopapular rashes on the face, anterior neck and chest. She had no history of prolonged medication intake prior to the onset of symptoms. Diagnostic evaluation revealed elevated levels of morning serum cortisol $(38.25 \mu \mathrm{g} / \mathrm{dL}$, normal value 5 to $25 \mu \mathrm{g} / \mathrm{dL}$ ) and fasting blood glucose (144 $\mathrm{mg} / \mathrm{dL}$ ). Computerized tomography (CT) scan of the brain did not reveal any mass lesion in the sella and parasellar areas, while abdominal CT scan showed enlargement of both adrenal glands. Plasma corticotrophin (ACTH) and pituitary magnetic resonance imaging (MRI) examination were performed, but the results were not available upon our review of her medical records. She was diagnosed with CS secondary to adrenal hyperplasia, and bilateral adrenalectomy was performed in July 1990. Histopathologic examination of the adrenals confirmed bilateral adrenal hyperplasia; no tumor was evident. After the surgery, she was given hydrocortisone intravenously, and was subsequently shifted to oral prednisone as maintenance. Her menstrual cycles eventually normalized.

Beginning in 1995, she noted generalized mucocutaneous hyperpigmentation. She took prednisone at $15 \mathrm{mg}$ /day irregularly, and was subsequently lost to follow-up from 2000. In February 2012, she began to experience headache, described as a sensation of heaviness, with a severity of $4 / 10$. This was accompanied by blurring of vision, nausea and generalized weakness. Physical examination showed normal vital signs and generalized skin hyperpigmentation (Figure 1). Neurologic examination showed full bilateral extraocular movement with no visual field loss. Laboratory results showed hypokalemia (3.3 $\mathrm{mmol} / \mathrm{L})$, hyponatremia $(123 \mathrm{mmol} / \mathrm{L})$, normal serum creatinine $(80.5 \mu \mathrm{mol} / \mathrm{L})$ and elevated morning ACTH $(1,250 \mathrm{pg} / \mathrm{mL}$, normal value 6 to $76 \mathrm{pg} / \mathrm{mL})$. Pituitary imaging study was recommended but not immediately performed because of limited finances.

The patient had frequent emergency room visits due to recurrent symptoms of weakness, nausea and vomiting, but had always deferred admission. She was given oral prednisone at a stress dose of $20 \mathrm{mg} /$ day for one week, subsequently tapered to $5 \mathrm{mg} /$ day as physiologic dose. Sodium chloride and potassium chloride tablets were also given for electrolyte correction. Cranial MRI eventually

Corresponding author: Daveric Ablis Pagsisihan, MD

Garde Drive, Bagumbayan, Taguig City

Tel. No.: (02)837-8471

Fax No.: (046)481-8000 loc 1224

E-mail:cir_evad@yahoo.com 
revealed a pituitary macroadenoma $(12.5 \mathrm{~mm} \times 16.3 \mathrm{~mm} \times$ $13.7 \mathrm{~mm}$ ) with no evidence of invasion of the cavernous sinuses and abnormal changes in the brain parenchyma (Figure 2). After imaging, oral dexamethasone was started by the attending neurosurgeon at $8 \mathrm{mg} /$ day. The dose was tapered to $4 \mathrm{mg} /$ day on follow-up. She was advised to undergo transphenoidal hypophysectomy for definitive management. The patient opted to continue with medical management temporarily due to financial issues. After 3 months of treatment, there was some improvement in headache, with no apparent change in mucocutaneus hyperpigmentation. When dexamethasone was withdrawn by the neurosurgery service, prednisone was resumed and maintained at physiologic dose.

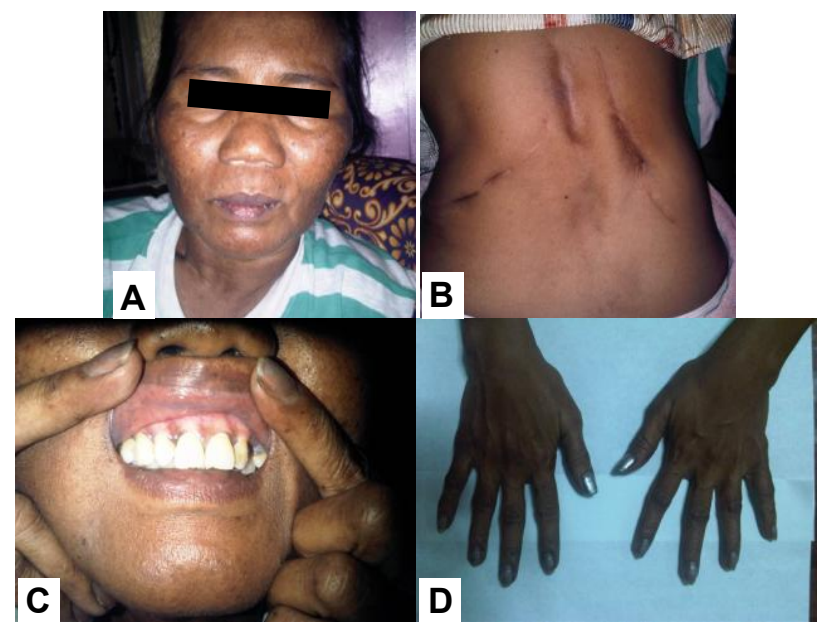

Figure 1. Generalized hyperpigmentation of the patient: face $(A)$, bilateral adrenalectomy surgical scar $(B)$, oral mucosa $(C)$, and hands $(D)$.

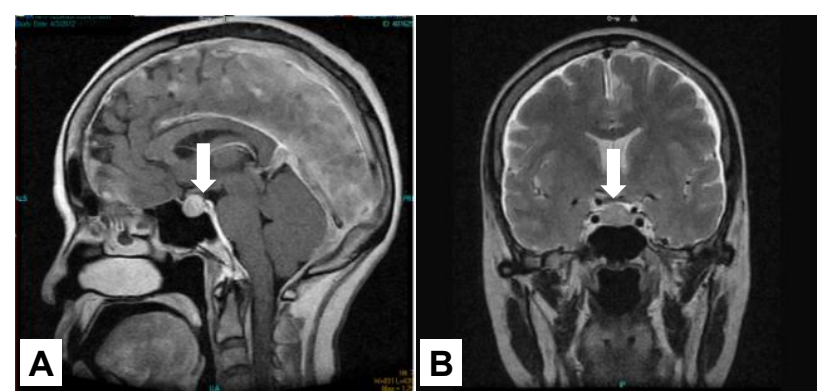

Figure 2. Cranial pituitary MRI showing the presence of a macroadenoma

\section{DISCUSSION}

Nelson's Syndrome has been reported to occur up to 24 years after total bilateral adrenalectomy. It is more common in women in their third to fourth decades of life. ${ }^{2,8}$ Mucocutaneus hyperpigmentation is usually obvious and is an important clinical manifestation. Bilateral adrenalectomy removes the inhibitory effect of adrenal cortisol on hypothalamic corticotropin-releasing hormone $(\mathrm{CRH})$ secretion and pituitary ACTH secretion. This results in increased circulating melanocyte stimulating hormone (MSH) and subsequent hyperpigmentation. An elevated ACTH level, therefore, is the most consistent and reliable diagnostic feature. ${ }^{2,9}$ Bitemporal hemianopsia, seen in 10 to $57 \%$ of patients, is due to compression of the optic chiasm. Invasion of the cavernous sinus, affecting the oculomotor, trochlear and abducens nerves, may present as diplopia. The enlarging tumor may cause panhypopituitarism, diabetes insipidus, headache (due to stretching of the diaphragma sellae), and pituitary apoplexy. ${ }^{5,8}$

In our patient's case, bilateral adrenalectomy was performed to treat CS secondary to adrenal hyperplasia. However, the cause of bilateral adrenal hyperplasia may have also been pituitary ACTH-dependent, despite the absence of a mass lesion in the cranial CT scan. Three decades ago, available imaging studies may have been unable to show the presence of a pituitary lesion causing CS. Recent studies have demonstrated that about $90 \%$ ACTH-secreting pituitary tumors are microadenomas, for which the sensitivity of a traditional cranial CT scan is relatively low at 20 to $60 \%$. Pituitary MRI is the imaging modality of choice to evaluate pituitary adenoma, with a better sensitivity of $70 \%{ }^{1}$ Pituitary MRI also has its limitations: it may not show an abnormality in up to $40 \%$ of cases if the size of the tumor is below the sensitivity of MRI. ${ }^{11}$ Bilateral adrenalectomy is a rational approach to treat hypercortisolism in adrenal hyperplasia and was previously the treatment of choice for CD. ${ }^{8,12}$ In this case, bilateral adrenalectomy was likely done due to the absence of an identifiable pituitary mass and the presence of adrenal hyperplasia. Whether surgical exploration of the pituitary gland by transphenoidal approach or total adrenalectomy is the better treatment option in such cases is still controversial. ${ }^{12}$ Plasma ACTH examination, if done then, would have aided in the selection of the appropriate treatment. In cases where surgical treatment is not feasible, "medical" adrenalectomy using an adrenolytic drug (mitotane), an adrenostatic drug (ketoconazole, metyrapone, aminoglutethimide, etomidate, trilostane) or glucocorticoid receptor antagonists (mifepristone) may be indicated, with careful consideration of the benefits and adverse effects of each drug. ${ }^{12,13}$

Several predictive factors for the development of NS after total bilateral adrenalectomy have been identified. These potentially useful predictors include: (1) a rapid increase in plasma ACTH concentration in the year after adrenalectomy, (2) residual pituitary tumor after transphenoidal surgery, (3) aggresive subtype of corticotrophinoma of Cushing's Disease (CD), and (4) lack of prophylactic neoadjuvant pituitary radiotherapy after bilateral adrenalectomy.,3,8,14After bilateral adrenalectomy, it is necessary to maintain lifelong glucocorticoid replacement with oral hydrocortisone (15 to $20 \mathrm{mg}$ upon awakening and 5 to $10 \mathrm{mg}$ in the early afternoon) and mineralocorticoid (fludrocortisone 0.05 to $0.2 \mathrm{mg} /$ day). ${ }^{10}$ No written data regarding the last maintenance dose of 
prednisone was available upon review of the patient's records. The patient also reported being poorly adherent to follow-up visits and medication. Because oral hydrocortisone and fludrocortisone are not available in the Philippines, the patient was maintained solely on prednisone.

Screening for the development of NS can be started 3 months after surgery with the use of $0800 \mathrm{H}$ plasma ACTH (before the morning steroid dose) and pituitary MRI. These examinations can be repeated 6 months postoperatively, then annually thereafter. Unfortunately, the patient was unable to return for follow-up after surgery, precluding further screening tests. The benefit of giving prophylactic pituitary radiotherapy after bilateral adrenalectomy to prevent or delay the development of NS is still controversial. . $^{14}$

Pituitary surgery, commonly through the transsphenoidal approach, is the treatment of choice in NS, especially if there is evidence of compression of the optic apparatus. ${ }^{4,15}$ The complications of this procedure include panhypopituitarism, cranial nerve palsy, leakage of cerebrospinal fluid and meningitis. ${ }^{4,8,15}$ Radiotherapy is a treatment option when surgery is unsuccessful or cannot be performed. Fractionated radiotherapy has long been used in the treatment of NS. In recent years, stereotactic gamma knife radiotherapy has also been widely used. Potential risks are panhypopituitarism, cranial nerve palsy, and developing secondary tumor. $4,8,16$

Selective somatostatin analogues, sodium valproate and rosiglitazone have been demonstrated to have effects on pituitary cells in vitro, but there is no data showing efficacy in the treatment of NS. $8,10,17$

Temozolomide, an alkylating agent, has been used to treat pituitary adenoma in 30 cases and pituitary carcinoma in 16 cases, including ACTH-producing pituitary adenoma or carcinoma. One reported case of aggressive NS treated with temozolamide showed a decrease in plasma ACTH level and reduction in tumor size after failure of surgery and radiotherapy. Temozolomide induces apoptosis, massive shrinkage and necrosis of target cells. The response to the therapy is influenced by the immunoexpression of $\mathrm{O}^{6}$-methylguanine-DNA methyltransferase (MGMT), a DNA repair enzyme, which counteracts the effect of temozolomide. More studies of temozolomide in NS treatment involving larger populations is needed..$^{18-21}$

\section{CONCLUSION}

We presented the classical history of NS after bilateral adrenalectomy for CS secondary to adrenal hyperplasia. Pituitary MRI and plasma ACTH results confirmed the diagnosis. Transsphenoidal hypophysectomy is the treatment of choice in our patient with NS. Knowing the potential development of NS after bilateral adrenalectomy, early surveillance by measuring morning plasma ACTH and pituitary MRI after bilateral adrenalectomy are strongly recommended. More recent medical options for treatment, including temozolomide, are being investigated for Nelson's syndrome.

References

1. Hornyak M, Weiss MH, Nelson DH et al. Nelson syndrome: Historical perspectives and current concepts. Neurosurg Focus 2007;23(3):1-9.

2. Hawn MT, Cook D, Deveney C et al. Quality of life after laparoscopic bilateraladrenalectomy for Cushing's disease. Surgery 2002;132:1064-9.

3. Assie G, Bahurel H, Coste J etal. Corticotroph tumor progression after adrenalectomy in Cushing's disease: A reappraisal of Nelson's syndrome. J Clin Endocrinol Metab 2007;92:172-9.

4. Barber TM, Adams E, Ansorge O et al. Review: Nelson's syndrome. Eur J Endocrinol 2010;163:495-507.

5. Saunders BD, Wainess RM, Dimick JB et al. Trends in utilization of adrenalectomy in the United States: Have indications changed? World J Surg 2004;28:1169-75.

6. Vargas ML, da Costa CV. Prevalence, etiology and clinical findings of Cushing's syndrome. Endocrinol Nutr 2009;56(1):32-9.

7. Santos EB, Rilloraza RS, Bandong-Reyes E. A case of hypercortisolism in Nelson's syndrome. Phil J Internal Medicine 1993;31:35-40.

8. Banasiak MJ, Malek AR. Nelson syndrome: Comprehensive review of pathophysiology, diagnosis, and management. Neurosurg Focus 2007;23(3):1-10

9. Barabash R, Moreno-Suárez FG, Rodríguez L et al. Case report: Nelson Syndrome: A rare cause of generalized hyperpigmentation of the skin. Actas Dermosifiliogr 2010;101(1):76-80.

10. Stewart PM. The Adrenal Cortex. In: Kronenberg HM, Melmed S, Polonsky KS, Larsen PR. Williams Textbook of Endocrinology. 11th ed. Philadel phia: Saunders Elsevier, 2008.

11. Arlt W. Disorders of the Adrenal Cortex. In: Longo DL, Fauci AS, Kasper DL, Hauser SL, Jameson JL, Loscalzo J. Harrison's Principles of Internal Medicine. 18th ed. Vol. 2. New York: Mc-Graw Hill, 2012.

12. Williams GH, Dluhy RG. Disorders of the Adrenal Cortex. In: Longo DL Fauci AS, Kasper DL, Hauser SL, Jameson JL, Loscalzo J. Harison's Endocrinology. 2nd ed. New York: Mc-Graw Hill, 2010.

13. Cavagnini F, Girarldi FP. Adrenal Causes of Hypercortisolism. In: Jameson JL, De Groot LJ. Endocrinology Adult and Pediatric. 6th ed. Volume II. Philadelphia: Saunders Elsevier, 2010.

14. Munir A, Newell-Price J. Nelson's syndrome. Arq Bras Endocrinol Metab2007;51(8):1392-6

15. Kelly PA, Samandouras G, Grossman AB et al. Neurosurgical treatment of Nelson's syndrome. J Clin Endocrinol Metab 2002;87:5465-9.

16. Vik-Mo EO, Oksnes M, Pedersen PH et al. Gamma knife stereotactic radiosurgery of Nelson syndrome. EurJEndocrinol 2009;160:143-8.

17. Munir A, Song F, Ince P et al. Ineffectiveness of rosiglitazone therapy in Nelson's syndrome. J Clin Endocrinol Metab 2007;92:1758-63.

18. Ortiz LD, Syro LV, Scheithauer BW et al. Temozolomide in aggressive pituitary adenomas and carcinomas. Clinics 2012;67(S1):119-23

19. Bush $\mathrm{ZM}$, Longtine JA, Cunningham $\mathrm{T}$ et al .Temozolomide treatment foraggressive pituitary tumors: Correlation of clinical outcome with $\mathrm{O}^{6}$ Methylguanine methyltransferase (MGMT) promoter methylation and expression .J Clin Endocrinol Metab 2010;95(11):E280-90.

20. Curtò L, Torre ML, Ferraù F et al.Temozolomide-induced shrinkage of a pituitary carcinoma causing Cushing's disease: Report of a case and literature review. The Scientific World Journal 2010;10:2132-8.

21. Moyes VJ, Alusi G, Sabin HI et al. Case report: Treatment of Nelson's syndrome with temozolomide. Eur JEndocrinol 2009;160:115-9 